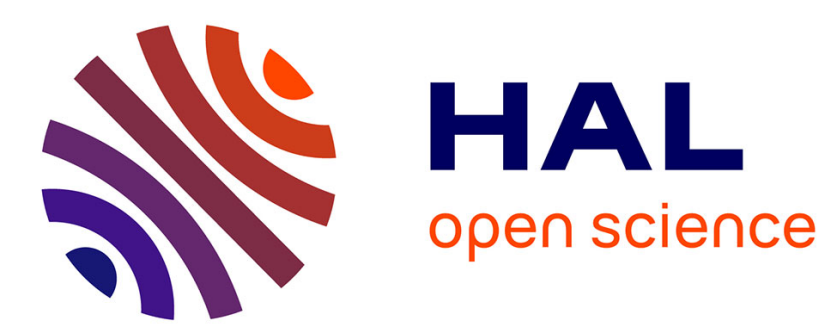

\title{
Investigation of thick sheet AHSS springback in combined bending under tension
}

Hocine Chalal, Sever-Gabriel Racz, Tudor Balan

\section{To cite this version:}

Hocine Chalal, Sever-Gabriel Racz, Tudor Balan. Investigation of thick sheet AHSS springback in combined bending under tension. Key Engineering Materials, 2012, 504-506, pp.6. 10.4028/www.scientific.net/KEM.504-506.791 . hal-01198952

\section{HAL Id: hal-01198952 \\ https://hal.science/hal-01198952}

Submitted on 14 Sep 2015

HAL is a multi-disciplinary open access archive for the deposit and dissemination of scientific research documents, whether they are published or not. The documents may come from teaching and research institutions in France or abroad, or from public or private research centers.
L'archive ouverte pluridisciplinaire HAL, est destinée au dépôt et à la diffusion de documents scientifiques de niveau recherche, publiés ou non, émanant des établissements d'enseignement et de recherche français ou étrangers, des laboratoires publics ou privés. 


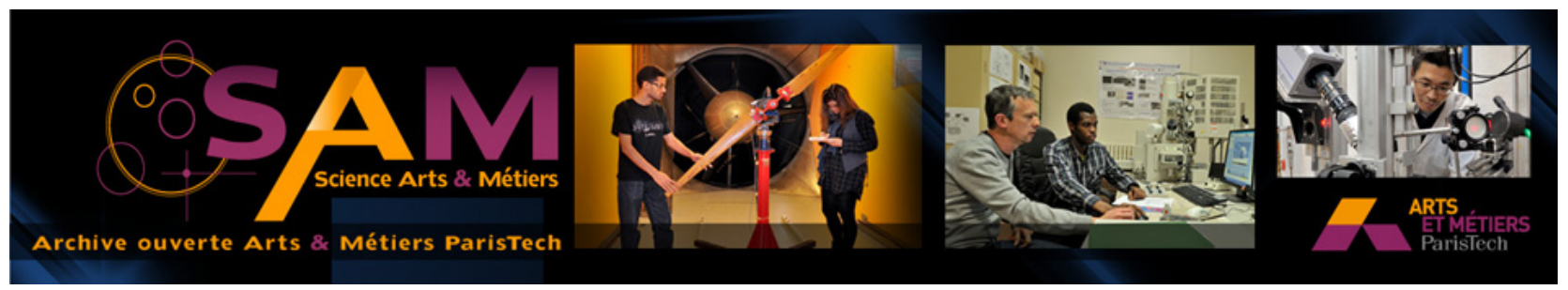

\section{Science Arts \& Métiers (SAM)}

is an open access repository that collects the work of Arts et Métiers ParisTech researchers and makes it freely available over the web where possible.

This is an author-deposited version published in: http://sam.ensam.eu

Handle ID: .http://hdl.handle.net/10985/10007

\section{To cite this version :}

Hocine CHALAL, Sever-Gabriel RACZ, Tudor BALAN - Investigation of thick sheet AHSS springback in combined bending under tension - Key Engineering Materials - Vol. 504-506, p.6 2012 


\title{
Investigation of thick sheet AHSS springback in combined bending under tension
}

\author{
Hocine Chalal ${ }^{1, a}$, Sever-Gabriel Racz ${ }^{2, b}$ and Tudor Balan ${ }^{3, c}$ \\ ${ }^{1}$ Laboratoire d'Étude des Microstructures et de Mécanique des Matériaux, LEM3, UMR CNRS \\ 7239, Arts et Métiers ParisTech - Metz, 4 rue Augustin Fresnel, 57078 Metz Cedex 03, France \\ 2 "Lucian Blaga" University of Sibiu, Faculty of Engineering, 4 str. Emil Cioran, 550025 Sibiu, \\ Romania
}

ahocine.chalal@ensam.eu, bgabriel.racz@ulbsibiu.ro, ctudor.balan@ensam.eu

Keywords: springback, bending-under-tension, AHSS, finite element simulation

\begin{abstract}
In this paper, we investigate the springback behavior of several advanced high-strength sheet steels (TRIP, Dual-Phase, ferrite-bainite) with thicknesses up to $4 \mathrm{~mm}$. Samples were tested by means of the bending-under-tension (BUT) test. The BUT has been extensively applied, in the literature, to relatively thin $(1 \mathrm{~mm}$ and thinner) sheet metals for automotive applications; the applicability of several guidelines from the literature was investigated in this work in the context of thick advanced high strength steel (AHSS) sheets and using a sample width of $12 \mathrm{~mm}$. The monotonic decrease of springback as back force increased was confirmed for this category of sheet steels, and a general trend for the non-linear influence of the tool radius was observed. With the selected sample width, the effect of the secondary curvature was negligible. Conclusions and simple guidelines are drawn from the analysis with industrial sheet forming applications in mind.
\end{abstract}

\section{Introduction}

Advanced high strength steels have been developed as a promising solution for the weight reduction of automotive body-in-white, which is aimed at reducing fuel consumption and emissions. While they are formed, these sheet materials exhibit a different behavior as compared to the more classical mild steels; increased springback is one of the main concerns. For the experimental investigation of springback, the bending-under-tension (BUT) test [1] allows to avoid almost completely the effect of friction and to precisely control the "blank holding" force, which is known to play an important role. In this investigation, several sheet AHSS and a CD06 mild steel are tested using the BUT test, using different tool radii and backforces. The aim of the tests is to investigate the applicability of some trends previously observed for thinner sheets; indeed, $2 \mathrm{~mm}$ and $4 \mathrm{~mm}$ thick sheets have been tested. Also, the width of the specimens was significantly reduced with respect to those reported in the literature, in an attempt to avoid the influence of secondary curvature variations on the springback results. The springback behavior is primarily governed by the stress distribution at the end of the process; structural effects like secondary curvature, when they occur, uselessly complicate the interpretation of the results and should be avoided.

The tests were conducted using the test facility at the IUL Institute, Dortmund University [2] for most materials, except for the DC06 material which was tested using the experimental setup of LEM3, ENSAM Metz [3] (Fig. 1). Four sheet materials were tested; their principal characteristics are summarized in Table 1. The two sheet materials with $2 \mathrm{~mm}$ thickness were the most thoroughly investigated. The remaining materials were tested over reduced ranges of tool radii (for small thicknesses) and back force (for the $4 \mathrm{~mm}$ sheet). Free roller tools were used with tool radii of 5, 10 and $15 \mathrm{~mm}$. Three levels of back force were set, determined for each material as pre-defined fractions of the force required to plastify the material. These so-called back force factors were equal to $0.5,0.8$ and 1.1. The specimens were $400 \mathrm{~mm}$ long and $12 \mathrm{~mm}$ wide. The tests were conducted with the front actuator in constant velocity control, and the back actuator in load control. All materials and conditions were tested with duplicate samples, at a bending angle of $90^{\circ}$. 

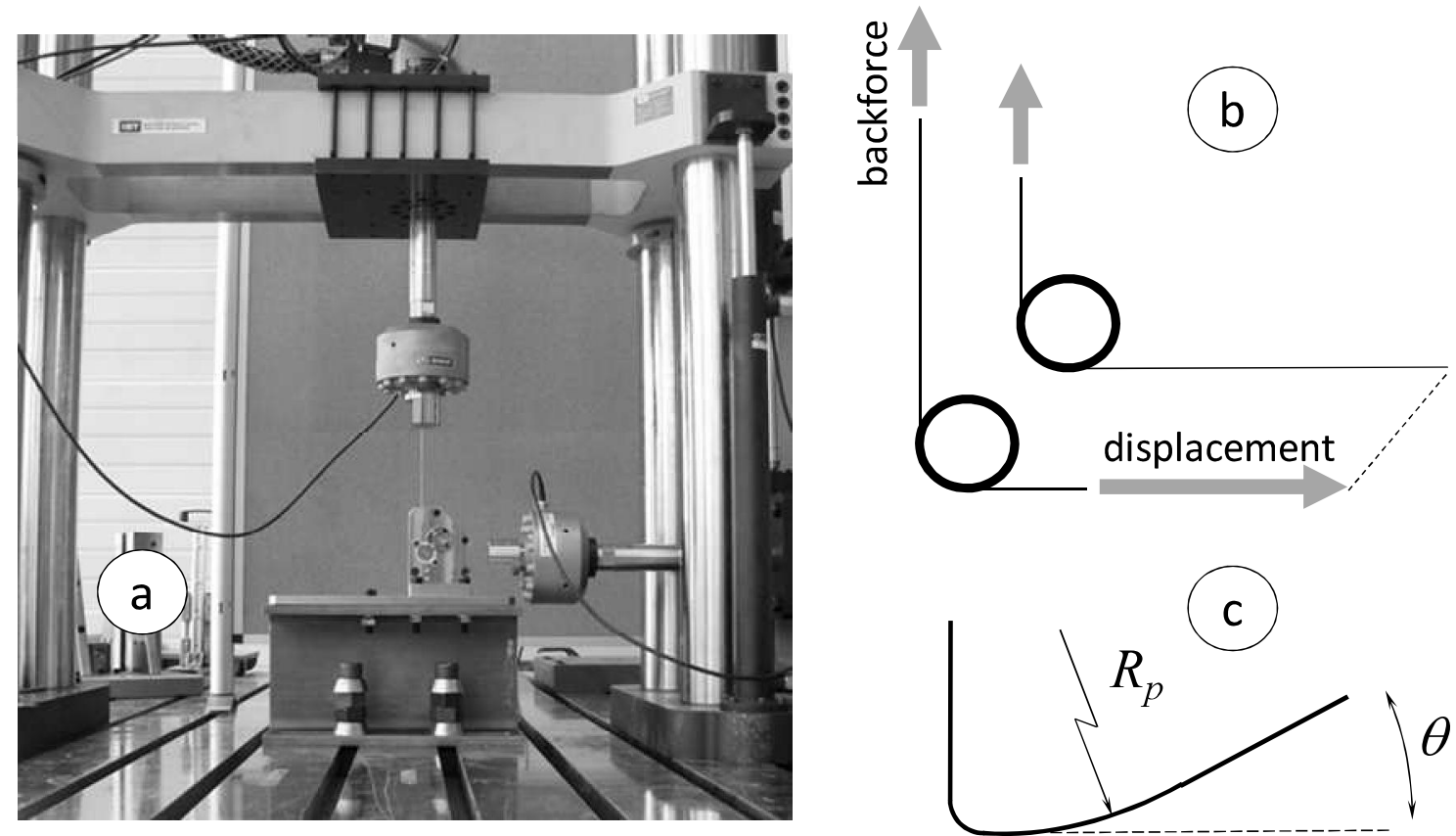

Fig. 1. Bending-under-tension experiment: (a) Bending-under-tension device on a biaxial testing machine at LEM3, ENSAM Metz; (b) Schematic representation of the test (beginning and end configurations); (c) Springback measures: curl radius and springback angle.

Table 1. Mechanical properties of the sheet steels used in the investigation [4].

\begin{tabular}{|r|r|r|r|r|}
\hline Material & $\begin{array}{r}\text { Thickness } \\
{[\mathrm{mm}]}\end{array}$ & $\begin{array}{r}\text { Yield stress } \\
{[\mathrm{MPa}]}\end{array}$ & $\begin{array}{r}\text { Ultimate tensile stress } \\
{[\mathrm{MPa}]}\end{array}$ & $\begin{array}{r}\text { Uniform elongation } \\
{[\%]}\end{array}$ \\
\hline FB & 4 & 494 & 586 & 13.3 \\
\hline DP & 2 & 489 & 780 & 13.8 \\
\hline TRIP B & 2 & 510 & 821 & 23.6 \\
\hline TRIP A & 1.26 & 506 & 859 & 22.1 \\
\hline DC06 & 0.8 & 163 & 290 & 23.6 \\
\hline
\end{tabular}

\section{Investigation of the secondary curvature}

Bending of sheet samples results in a secondary curvature, which has a non-negligible effect on springback in some particular cases [5]. This effect is due to the modification of the bending stiffness of the cross-section of the sample, when secondary curvature appears. The new shape of the cross-section depends on Searle's dimensionless parameter $\frac{w}{R_{p}} \cdot \frac{w}{t}$, were $w, t$ and $R_{p}$ are the sheet width, thickness and radius of the primary bending curvature, respectively [6]. For values smaller than unity, the secondary curvature is constant, while for values larger than 20 , the secondary curvature vanishes in the central area and increases near the edges. For the current experiments, Searle's parameter was less than unity in all cases, ranging from 0.8 (for the $1.2 \mathrm{~mm}$ TRIP A, $R=5$ $\mathrm{mm}, k=0.5$ ) to 0.008 ( $4 \mathrm{~mm} \mathrm{FB}, R=10 \mathrm{~mm}, k=0.5$ ). Consequently, the secondary curvature of the cross-section was almost constant, and it could be determined by measuring its height at the middle of the cross-section (Fig. 2). Then, the area moment of inertia of the cross-section could be approximated analytically with respect to the shifted center of gravity, supposing that its curvature radius is constant and that the width $w$ does not change (see Fig. 2 for geometry and notations): 


$$
I_{z z G}=I_{z z 0}+y_{G}^{2} w t \quad ; \quad I_{z z 0}=\frac{1}{8}(\beta+\sin \beta) \frac{w t}{\beta}\left(4 \frac{w^{2}}{\beta^{2}}+t^{2}\right) \text {, }
$$

where the position of the centre of gravity $G$, with respect to the centre of curvature $O$, is:

$$
y_{G}=\frac{1}{w} \sin \frac{\beta}{2}\left(2 \frac{w^{2}}{\beta^{2}}+\frac{t^{2}}{6}\right) \text {. }
$$

Then, the relative bending stiffness of the final cross-section, as compared to the original one, can be expressed with the following formula, where a possible variation of the Young modulus is also taken into account:

$$
\frac{W}{W_{0}}=\frac{E}{E_{0}} \cdot \frac{I_{z z G}}{I_{r e f}} \quad ; \quad I_{r e f}=\frac{t_{0}^{3} w_{0}}{12} .
$$
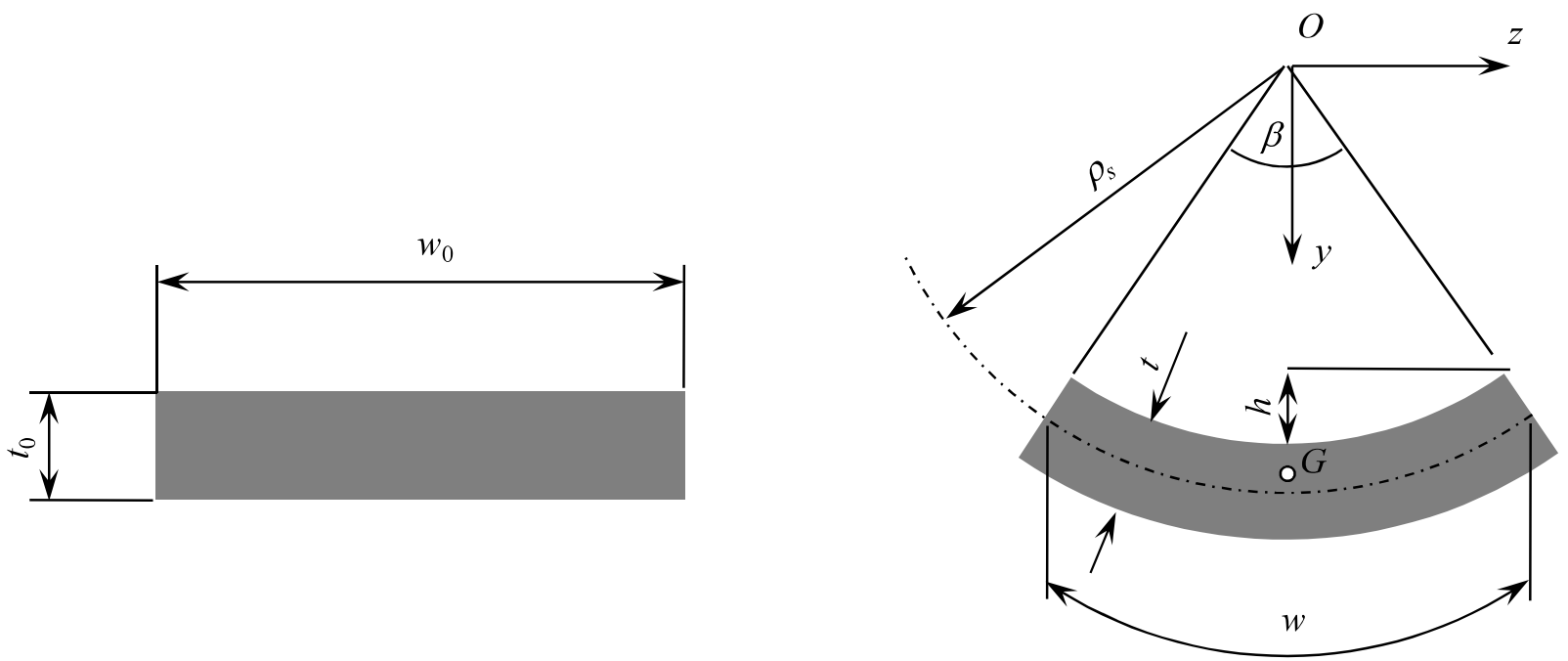

Fig. 2. Cross-section of the samples before (left) and after (right) the test.

Fig. 3 shows the variation of the bending stiffness with the secondary curl height. It appears that for the chosen $12 \mathrm{~mm}$ sample width, and in the range of measured secondary curl heights (less than $0.24 \mathrm{~mm}$ in all cases), the stiffness variation is very small for sheets $2 \mathrm{~mm}$ thick or more, and can be neglected in the interpretation; this was the aim of the current section.

The samples were further investigated by thickness measurements. After the tests, the thickness was reduced for all the samples. The thickness reduction ranged from $6 \%$ to $22 \%$ for the $2 \mathrm{~mm}$ thick sheets; this considerably reduces the stiffness of the sample, as illustrated in Fig. 4. Consequently, thickness variation is probably one of the factors preventing accurate springback predictions by some analytical methods in cases with small values of the tool radius vs. thickness ratio.

\section{Springback measures and discussion}

It is often reported in the literature that springback diminishes quasi-linearly with back force. In the case of some aluminum alloys, however, non-linear evolutions were observed for back force factors larger than $0.8[5,7]$. Another important factor of influence is the tool radius vs. thickness ratio. These two factors were particularly studied in this investigation, in order to determine their influence for the thick sheet AHSS. 


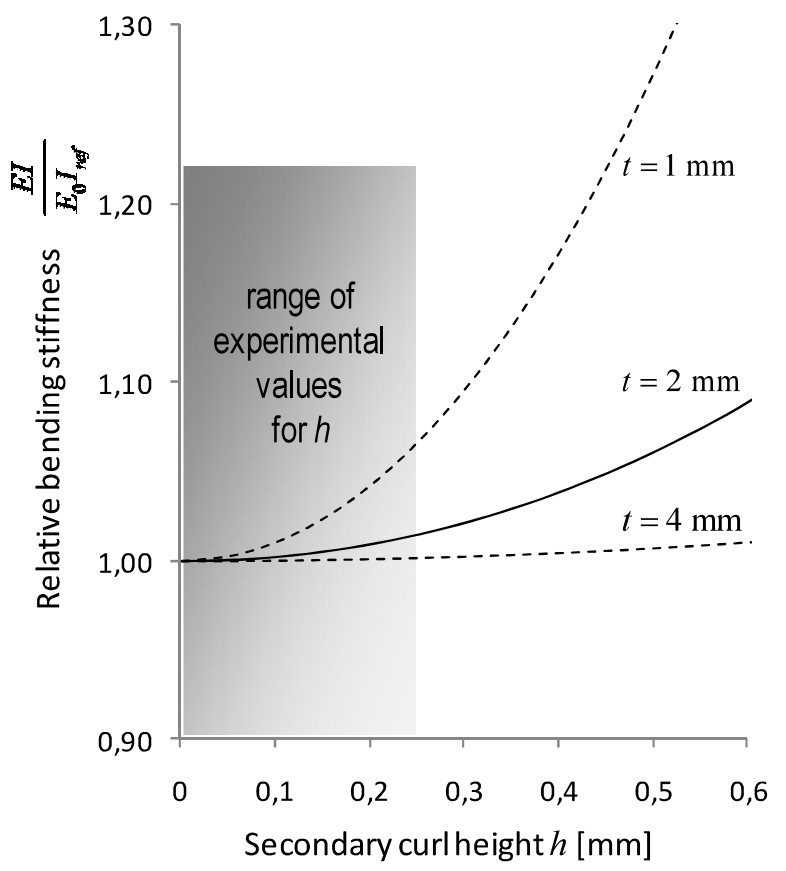

Fig. 3. Effect of the secondary curvature of the samples on their stiffness in bending.

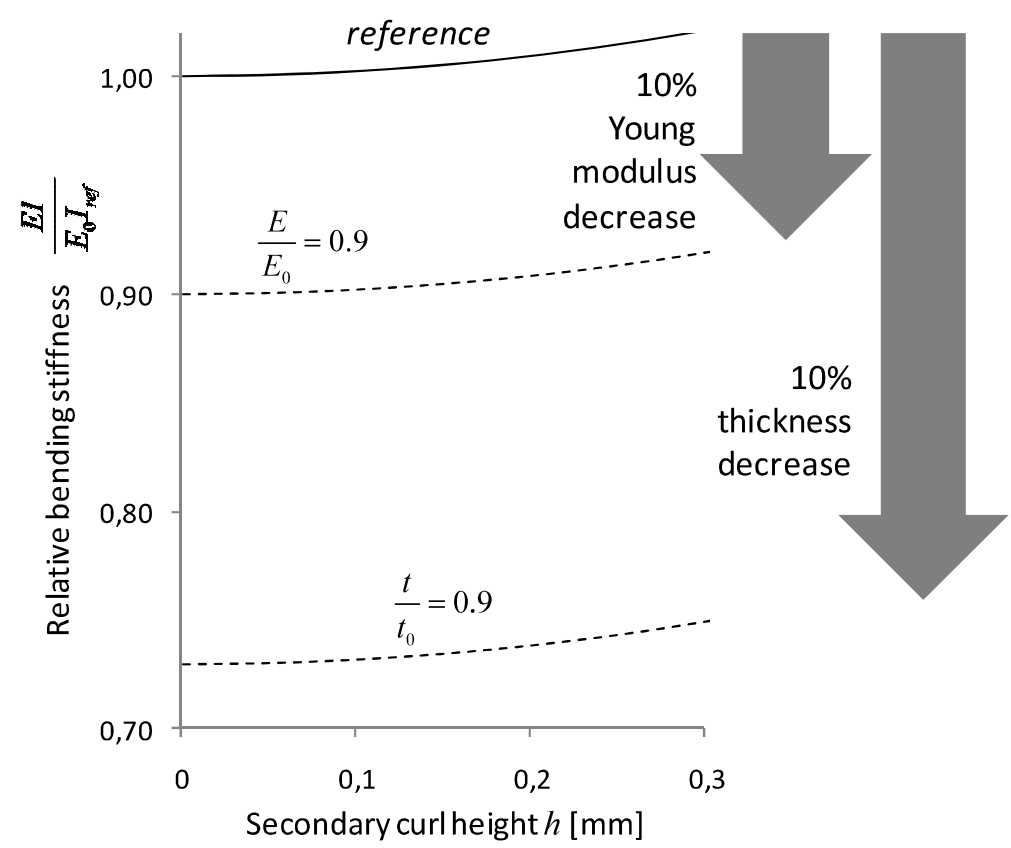

Fig. 4. Effect of the variation of Young modulus and thickness, respectively, on bending stiffness.

Fig. 5 shows the effect of the $R / t$ ratio on the measured springback angles. The results for all the materials are overlapped in order to observe the general trends. The three plots represent tests performed with the same backforce factor. These results confirm that increasing the $R / t$ ratio slightly reduces the springback in most cases. However, for $R / t$ smaller than a certain limit, the springback angle strongly decreases as $R / t$ decreases. The critical value seems to be about 4 ...6 for all of the studied materials, in spite of their very different thickness and mechanical properties. 


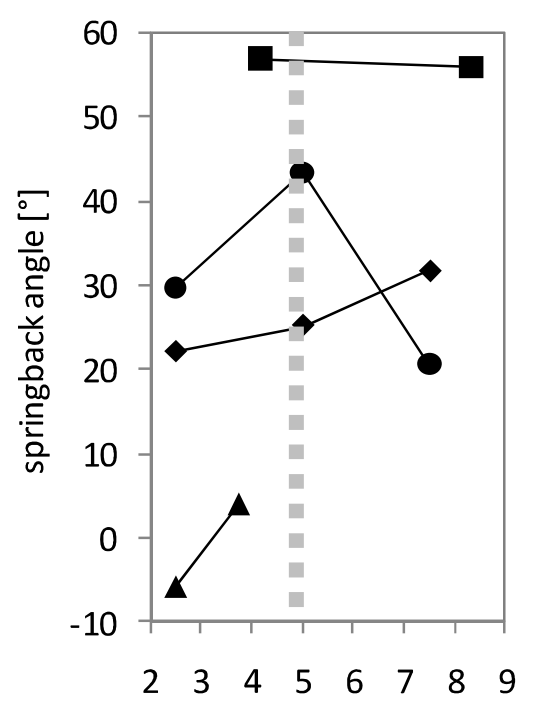

$\mathrm{R} / \mathrm{t}$

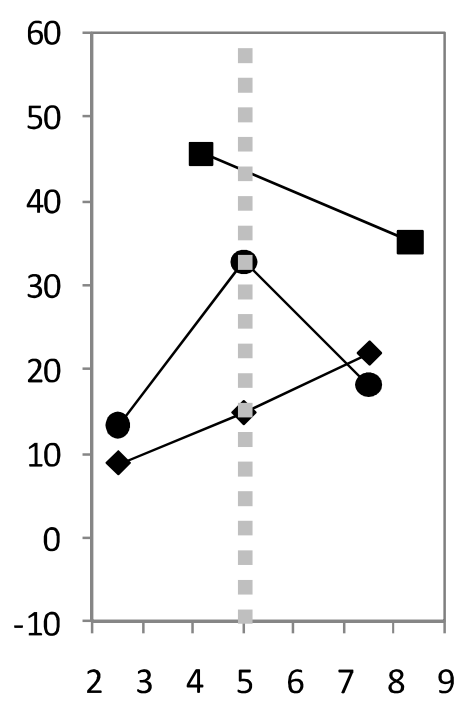

$\mathrm{R} / \mathrm{t}$

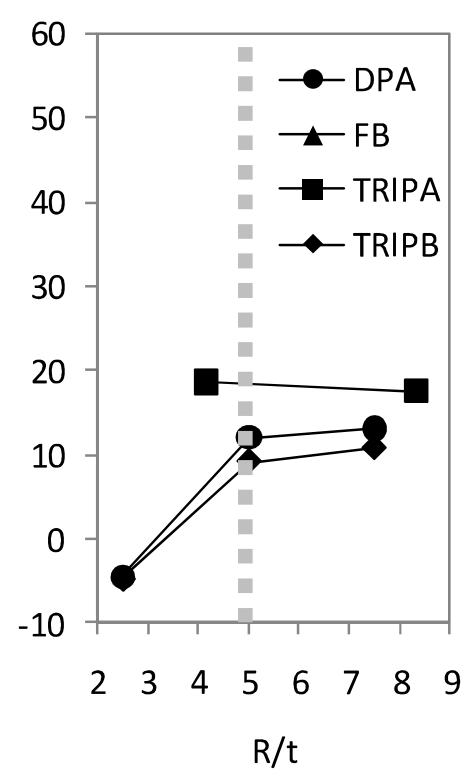

$\mathrm{R} / \mathrm{t}$

Fig. 5. Influence of the die radius vs. sheet thickness ratio on the springback angles, for back force factors equal to 0.5 (left), 0.8 (center) and 1.1 (right).

Fig. 6 shows the measured springback angles as function of the applied backforce. It appears that the influence of the applied back force was quasi-linear in all cases. As expected, larger $k$ values produced smaller springback, and the differences due to the different materials or tool radii also diminished as $k$ increased. Also, the range of springback angles diminished as $k$ increased; $k=0.5$ produced the largest experimental springback angle of $57^{\circ}$, which was three times larger than the $19^{\circ}$ maximum for $k=1.1$.

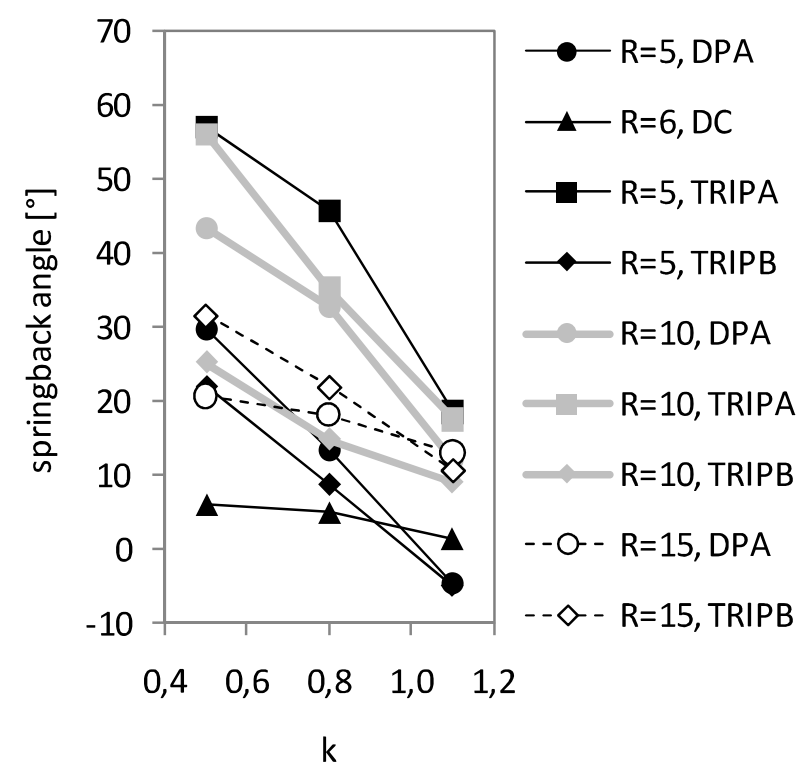

Fig. 6. Influence of the back force factor $k$ on the side-wall curvature. 


\section{Summary and conclusions}

The springback of several relatively thick AHSS sheets was investigated by means of the bending under tension test. The experiments confirmed that when sheet tension increases, springback decreases almost linearly. In general, springback decreases for larger tool radii (this effect is less significant than that of sheet tension). For small $R / t$ ratios, however, this trend is completely reversed. Below a critical ratio, smaller tool radii induced a decrease in springback - even leading to "springforward". For all of the tested materials, thicknesses, and sheet tensions, the critical value was approximately $R / t=5$. For the chosen sample width, the Searle parameter was less than unity in all cases. Consequently, secondary curvature had little influence on the results and no interference from changes in cross-section shape was observed when studying the effects of the other parameters. A thickness reduction was systematically observed, which has an influence on springback. This is believed to restrict the application of simple analytical solutions for small $R / t$ and $w / t$ values. Numerical investigations are under progress to further investigate and interpret these experimental observations.

\section{Acknowledgements}

The authors are grateful to X. Lemoine (ArcelorMittal Maizière R\&D Automotive Products) for providing the materials, to M. Brunet (LaMCoS, INSA Lyon) for providing the material parameters, and to T. Cwiekala (IUL Dortmund) for his valuable help with experiments. This work has been financially supported by the Agence Nationale de la Recherche, France, through the RNMP project "FORMEF".

\section{References}

[1] T. Kuwabara, S. Takahashi, K. Akiyama, Y. Miyashita, 2D Springback analysis for stretchbending processes based on total strain theory, SAE Technical paper 950691 (1995) 1-10.

[2] M. Kleiner, M. Schikorra, R. Govindarajan, A. Brosius, Springback analysis of sheet metals regarding material hardening, in Proc. 11th Int. Conf. on Sheet Metal, p. 712-728 (2005).

[3] S.G. Racz, S. Khan, H. Chalal, F. Abed-Meraim, T. Balan, Prediction of springback after drawbending test using different material models, in Proc. Conf. on Adv. Materials Proc. Technol., Paris, p. 419-424 (2010).

[4] X. Lemoine, Steels and experiments, Formef project report, ArcelorMittal R\&D, Maizières-lèsMetz, 2006.

[5] J.F. Wang, R.H. Wagoner, D.K. Matlock, F. Barlat, Anticlastic curvature in draw-bend springback, Int. J. Solids Struct. 42 (2005) 1287-1307.

[6] G. Searle, Experimental Elasticity: A Manual for the Laboratory, Cambridge University Press, Cambridge, 1908.

[7] W.D. Carden, L.M. Geng, D.K. Matlock, R.H. Wagoner, Measurement of springback, Int. J. Mech. Sci. 44 (2002) 79-101. 